\title{
Determination of 10-hydroxystearic, 10-ketostearic, 8-hydroxypalmitic, and 8-ketopalmitic acids in milk fat by solid-phase extraction plus gas chromatography-mass spectrometry
}

\author{
G. Márquez-Ruiz, ${ }^{*}$ V. Rodríguez-Pino, ${ }^{*}$ and M. A. de la Fuente ${ }^{1}$ \\ *Instituto de Ciencia y Tecnología de Alimentos y Nutrición (CSIC), José Antonio Novais 10, 28040, Madrid, Spain \\ †Instituto de Investigación en Ciencias de la Alimentación (CSIC-UAM), Nicolás Cabrera, 9. Universidad Autónoma de Madrid, 28049 Madrid, \\ Spain
}

\section{ABSTRACT}

Fatty acids (FA) bearing oxygenated functions and present in esterified form in triacylglycerols are widespread in nature but very little is known about their occurrence in dairy products. A method based on gas chromatography (with flame ionization detector and mass spectrometry detectors), including the previous isolation of polar FA methyl esters by solid-phase extraction, was applied to quantify oxygenated FA in milk fat. Samples obtained from ewes and goats fed with a variety of oil sources were studied. Fatty acids identified were 8-ketopalmitic, 8-hydroxypalmitic, 10-ketostearic, and mainly 10-hydroxystearic acids. The highest levels of 10-ketostearic acid were obtained in milk from animals fed olive oil (up to 1.5\%) and from those fed long-chain n-3 FA-enriched diets (0.5-1.0\%). In all samples, 10-hydroxystearic acid, not reported so far in milk, was the second most abundant oxygenated FA (up to $0.8 \%$ ). The high correlation obtained between contents of 10-ketostearic and 10-hydroxystearic acids would confirm the existence of a common pathway of formation in the rumen, whereas the presence of 8-ketopalmitate and 8-hydroxypalmitate could be putatively attributed to mechanisms of $\beta$-oxidation in the tissues. The influence of cis-9 C18:1 and trans-10 C18:1 as precursors of these compounds in milk and the metabolic pathways involved in their formation are discussed.

Key words: 10-ketostearic acid, 10-hydroxystearic acid, milk fat, trans-10 C18:1

\section{INTRODUCTION}

Dairy fat is regarded as one of the most complex naturally occurring fats and oils, because of the large number of fatty acids (FA) with a variety of structures present in esterified form in triacylglycerols. Using a

Received April 6, 2011.

Accepted June 8, 2011.

${ }^{1}$ Corresponding author: mafl@if.csic.es combination of techniques, researchers have identified approximately $400 \mathrm{FA}$ in milk (Jensen, 2002). Fifteen FA are present at or above $1 \%$ concentration but the vast majority are found in small amounts (less than $0.1 \%)$. Among these minor components are oxygenated structures, mainly keto and hydroxy acids. Keto acids can be precursors of flavor compounds, such as methyl ketones, which contribute greatly to the organoleptic properties of some cheeses. Hydroxy FA are of increasing interest because some studies have attributed to these compounds inhibitory effects on cell proliferation and viability (Casali et al., 1994; Gesmundo et al., 1994) as well as potent cytotoxic effects on human melanoma development (Abe and Sugiyama, 2005).

Although the formation of keto FA by some species of ruminal microorganisms has been well documented (Hudson et al., 1995, 2000; Jenkins et al., 2006; McKain et al. 2010), little is known about the quantitative significance and variability of keto FA in dairy products. Weihrauch et al. (1974) tentatively identified some keto FA in milk but no quantitative data were supplied, whereas Brechany and Christie (1992) detected trace amounts of a variety of these compounds in cheeses. Little data are likewise available on the occurrence and quantities of hydroxy FA in milk (Parks, 1977; Jenske and Vetter, 2008). Oxygenated FA are originated in the rumen as intermediates of the biohydrogenation processes of the unsaturated FA from ruminant diet. However, the pathways of formation are not completely clarified. Characterizing the formation of intermediates and production of end products arising from the biohydrogenation of lipids in the rumen is paramount to attempts to enhance the nutritional attributes of ruminant milk fat. Thus, it would be useful to gain more information about such minor FA and on the factors that may influence their occurrence in dairy products.

The aim of this work was to determine the presence of keto and other oxygenated FA in milk fat and to study composition differences relative to the source of oils in the ruminant diet. Owing to the small contribution of these FA to milk lipids, essentially esterified 
Table 1. Milk fat samples analyzed

\begin{tabular}{|c|c|c|c|}
\hline Group & Sample & $\begin{array}{l}\text { Type of dietary } \\
\text { lipid supplementation, } \\
\% \text { in DM }\end{array}$ & $\begin{array}{c}\text { Period of } \\
\text { Supplementation, d }\end{array}$ \\
\hline \multirow[t]{4}{*}{1} & 1 & Olive oil $(3 \%)$ & 48 \\
\hline & 2 & Soybean oil $(3 \%)$ & 48 \\
\hline & 3 & Linseed $(3 \%)$ & 54 \\
\hline & 4 & Palm oil $(3 \%)$ & 48 \\
\hline \multirow[t]{4}{*}{2} & 1 & None & 21 \\
\hline & 2 & High-oleic sunflower oil (4\%) & 21 \\
\hline & 3 & Sunflower oil $(4 \%)$ & 21 \\
\hline & 4 & Linseed oil $(4 \%)$ & 21 \\
\hline \multirow[t]{4}{*}{3} & 1 & None & 0 \\
\hline & 2 & Sunflower oil $(5.1 \%)$ & 7 \\
\hline & 3 & Sunflower oil $(5.1 \%)$ & 14 \\
\hline & 4 & Sunflower oil (5.1\%) & 28 \\
\hline \multirow[t]{7}{*}{4} & 1 & None & 7 \\
\hline & 2 & Sunflower oil $(2.5 \%)+$ microalgae $(0.8 \%)$ & 7 \\
\hline & 3 & Sunflower oil $(2.5 \%)+$ microalgae $(0.8 \%)$ & 7 \\
\hline & 4 & Sunflower oil $(2.5 \%)+$ microalgae $(0.8 \%)$ & 21 \\
\hline & 5 & Sunflower oil $(2.5 \%)+$ microalgae $(0.8 \%)$ & 21 \\
\hline & 6 & Sunflower oil $(2.5 \%)+$ microalgae $(1.6 \%)$ & 21 \\
\hline & 7 & Sunflower oil $(2.5 \%)+$ microalgae $(1.6 \%)$ & 21 \\
\hline \multirow[t]{4}{*}{5} & 1 & Olive oil Ca soaps $(3 \%)$ & 48 \\
\hline & 2 & Olive oil Ca soaps $(3 \%)$ & 48 \\
\hline & 3 & Olive oil Ca soaps $(3 \%)$ & 48 \\
\hline & 4 & Olive oil Ca soaps ( $3 \%)$ & 48 \\
\hline
\end{tabular}

in triacylglycerols, their quantification poses a great challenge for instrumental analysis. For this purpose, a highly sensitive and selective method for the quantification of epoxy, keto, and hydroxy FA in thermoxidized oils and fats was applied (Marmesat et al., 2008). This method, based on derivatization to FA methyl esters (FAME) and GC includes the isolation of minor polar FA containing oxygenated structures by solid-phase extraction (SPE) for concentration purposes and to prevent analytical interferences caused by most abundant, non-oxygenated FA naturally occurring in milk fat.

\section{MATERIALS AND METHODS}

\section{Sample Selection}

This work was made up of 23 milk fats originating from 5 previous studies. Fats were placed in amber vials, blanketed with a stream of $\mathrm{N}_{2}$, and stored at $-17^{\circ} \mathrm{C}$ until analysis. Milk samples were selected to cover the effects of different types of dietary oil supplements on milk fat FA profiles (Table 1). Briefly, group 1 was used to determine the effect of a diet supplemented with $3 \%$ olive, soybean, palm, and linseed oils (DM basis) on the composition of individual ewe milk fats. Group 2 was used to evaluate diet supplementation with $4 \%$ high-oleic sunflower, linseed, and sunflower oils (DM basis) on individual goat milk fats. Group 3 was used to monitor for $28 \mathrm{~d}$ the effect of the dietary inclusion of $5.1 \%$ sunflower oil (DM basis) on ewe bulk milk fat composition. Group 4 was used to evaluate the effects of a combination of sunflower oil (2.5\%) and microalgae, a source of long-chain n-3 FA, on bulk ewe milk fats. Finally, Group 5 was used to evaluate the effects of feeding olive oil administered as Ca soaps on the individual ewe milk fats. In addition, some control samples from animals fed without lipid supplementation were analyzed for comparison purposes.

\section{Determination of Milk Fatty Acid Profile by GC}

Milk fat was extracted following the method of Luna et al. (2005) and FAME were prepared by base-catalyzed methanolysis of the glycerides $(\mathrm{KOH}$ in methanol) according to the ISO-IDF (2002a) procedure.

After derivatization, the total FA profile was recorded by analysis of FAME on a gas-liquid chromatograph (Agilent 6890 N Network System; Agilent Technologies Inc., Palo Alto, CA) with autoinjector, fitted with a flame ionization detector onto a CP-Sil 88 fused silica capillary column $(100 \mathrm{~m} \times 0.25 \mathrm{~mm}$; Varian Inc., Middelburg, the Netherlands). Helium was the carrier gas at an inlet pressure of $235.8 \mathrm{kPa}$ and a split ratio of 1:100. The injector and detector temperature was $250^{\circ} \mathrm{C}$. The total time of the chromatographic program was 125 min and the initial oven temperature was $160^{\circ} \mathrm{C}$. After $80 \mathrm{~min}$, the oven temperature was raised at $10^{\circ} \mathrm{C} /$ min to $210^{\circ} \mathrm{C}$ and then held for $40 \mathrm{~min}$. Quantification of individual FAME was made by reference to a milk fat with a known composition (CRM 164; European 
Community Bureau of Reference, Brussels, Belgium) according to the ISO-IDF (2002b).

\section{Determination of Oxygenated Fatty Acids by SPE-GC}

Fatty acid methyl esters were obtained by transmethylation with sodium methoxide at room temperature according to Berdeaux et al. (1999). Three-hundred milligrams of milk fat were weighed into a screw-capped centrifuge tube and $3 \mathrm{~mL}$ of tert-butyl methyl ether (TBME) was added. Then, $1.5 \mathrm{~mL}$ of $0.2 \mathrm{M}$ sodium methoxide (NaOMe) solution in methanol was added, the tube closed, shaken for $1 \mathrm{~min}$, and allowed to stand at room temperature $\left(23 \pm 2^{\circ} \mathrm{C}\right)$ for $2 \mathrm{~min}$. For neutralization purposes, $0.1 \mathrm{~mL}$ of $0.5 \mathrm{M} \mathrm{H}_{2} \mathrm{SO}_{4}$ was added and the mixture was shaken for a few seconds. Finally, $3 \mathrm{~mL}$ of water was added, shaken for $10 \mathrm{~s}$ and centrifuged at $3,600 \times g$ for $1 \mathrm{~min}$. The organic layer was separated and evaporated to dryness under nitrogen.

Determination of oxygenated FAME was carried out following the methodology of Marmesat el al. (2008) for quantification of epoxy, keto, and hydroxy FAME, with slight modifications. Fatty acid methyl esters were fractionated by SPE using SPE silica cartridges (1 g of silica; Sep-Pak cartridges, Waters Corp., Milford, MA). An aliquot of $100 \mathrm{mg}$ of FAME was weighed, dissolved in $2 \mathrm{~mL}$ of $n$-hexane-diethyl ether $(98: 2, \mathrm{vol} /$ vol) and placed on the silica cartridge. The solvent passed through while FAME were retained on the column. The nonpolar fraction was eluted with $15 \mathrm{~mL} n$ hexane-diethyl ether $(98: 2, \mathrm{vol} / \mathrm{vol})$. The polar fraction, which comprises FAME with oxygenated functions, was eluted with $25 \mathrm{~mL}$ of diethyl ether.

The separation of the fractions was confirmed by thin-layer chromatography using silica gel 60 plates $(5 \mathrm{~cm} \times 10 \mathrm{~cm}$ plates, $0.25-\mathrm{mm}$ thickness $)$ acquired from Merck KGaA (Darmstadt, Germany). The plate was deliberately overloaded, eluted with hexane-diethyl ether-acetic acid (80:20:1, vol/vol/vol) and visualized with iodine vapor. A neat separation between the 2 fractions was normally found. Following evaporation of solvent under nitrogen, a volume of $500 \mu \mathrm{L}$ of a diethyl ether solution containing $500 \mu \mathrm{g} / \mathrm{mL}$ of $\mathrm{C} 21: 0$ (Nu-Chek-Prep Inc., Elysian, MN) was added to the polar fraction before GC analyses. A volume of $1 \mathrm{~mL}$ of diethyl ether was added to $50 \mathrm{mg}$ of total FAME and the nonpolar fractions for GC analyses.

Total, nonpolar and polar FAME were analyzed by GC using an Agilent 6850 chromatograph (Agilent Technologies Inc.), fitted with a flame ionization detector onto a DB-Wax fused-silica capillary column (30 $\mathrm{m} \times 0.32 \mathrm{~mm}$; J\&W Scientific Products GmbH, Köln, Germany). The injector and detector temperature was $250^{\circ} \mathrm{C}$. The analyses were run using hydrogen as carrier gas at $1 \mathrm{~mL} / \mathrm{min}$, a split ratio of 1:40, and isothermal conditions $\left(240^{\circ} \mathrm{C}\right)$ for $10 \mathrm{~min}$. The injection volume was $1.0 \mu \mathrm{L}$. Quantification of oxygenated FAME in the polar fraction was carried out as described by Marmesat et al. (2008), using C21:0 as internal standard.

\section{GC-MS Analyses}

Polar FAME were analyzed onto a DB-Wax fused-silica capillary column $(30 \mathrm{~m} \times 0.32 \mathrm{~mm}, \mathrm{~J} \& W$ Scientific Products $\mathrm{GmbH}$ ) on an Agilent 7890A chromatograph (Agilent Technologies Inc.) with a triple axis mass spectrometry Agilent detector (5975C inert MSDM; Agilent Technologies Inc.). The filament trap current was 400 $\mu \mathrm{A}$ at $70 \mathrm{eV}$. Injections were under data system control with an autoinjector. The column was held at $240^{\circ} \mathrm{C}$ for $10 \mathrm{~min}$. Helium was the carrier gas with a column inlet pressure set at $68.4 \mathrm{kPa}$ and a split ratio of 1:40. The injection volume was $1.0 \mu \mathrm{L}$. Wiley 275 (http:// eu.wiley.com) and NIST 05 (www.nist.gov/srd/nist1a. htm) libraries were used to identify the mass spectra.

\section{Statistical Analyses}

Correlation between selected FA was investigated with the CORR procedure (SAS Institute, 2004). Statistical significance was considered at $P<0.05$.

\section{RESULTS AND DISCUSSION}

\section{Determination of Oxygenated FAME in Polar Fractions}

Figure 1 shows GC chromatograms of total FAME, the nonpolar FAME fraction, and polar FAME fraction, illustrating the advantages of the analytical procedure applied to determine minor oxygenated FA in milk fats. The milk fat sample shown belongs to group 3 , specifically from ewes fed a diet supplemented with $5.1 \%$ sunflower oil for $28 \mathrm{~d}$.

Separation of the abundant nonpolar fraction, comprising major FA, which make up at least $98 \%$ of total FAME, enhanced possibilities of detection and quantification of minor oxygenated FAME, which were concentrated in the polar FAME fraction. In addition, interferences due to minor nonpolar long-chain FAME eluting at similar retention times as those of the polar compounds of interest could be avoided. As can be observed in Figure 1, total FAME were largely comprised of nonpolar FAME, the most abundant fraction, and the bulk of them eluted before $5 \mathrm{~min}$. Some of the small peaks found in total FAME at retention times longer than 5 min eluted in the nonpolar fraction, such as $\mathrm{C} 22: 0$ and $\mathrm{C} 23: 0$, this latter practically coeluting with 


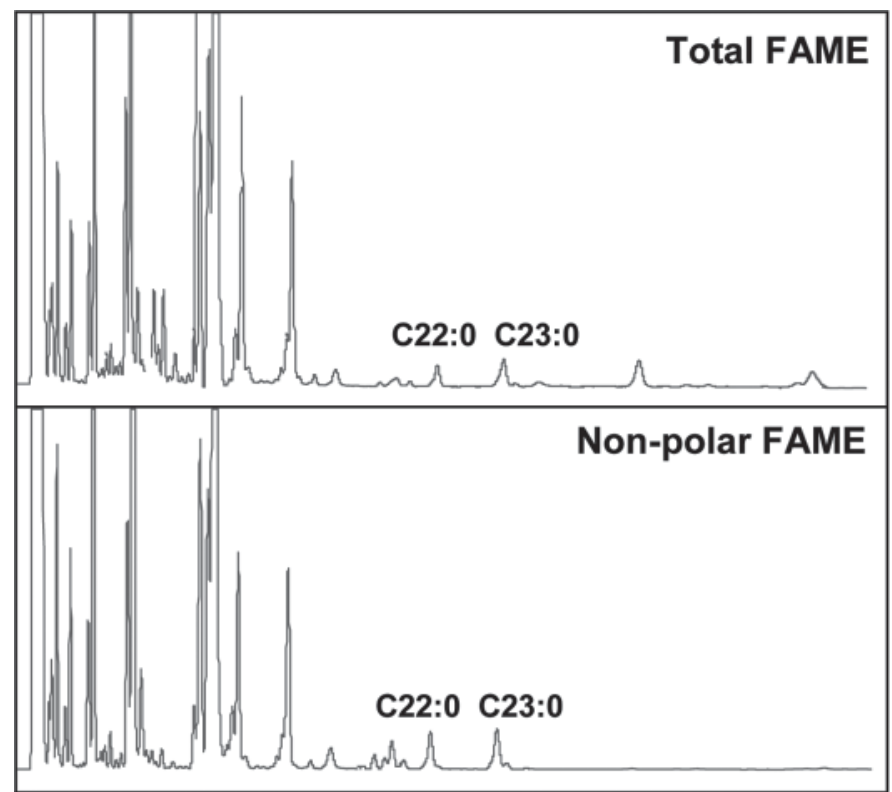

Polar FAME

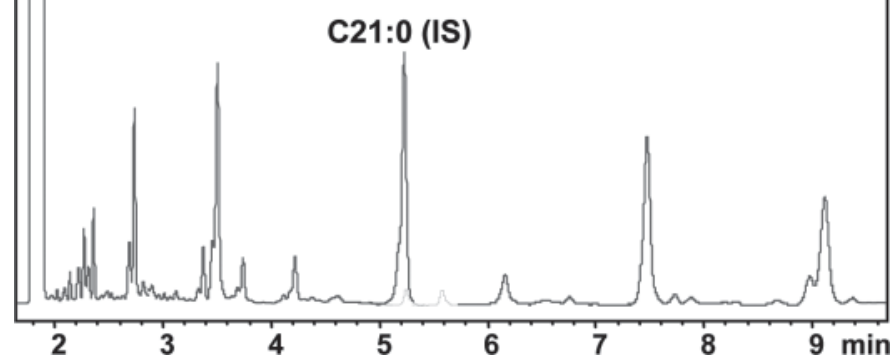

Figure 1. Gas chromatograms of the total fatty acid methyl esters (FAME) and FAME fractions isolated by solid-phase extraction (nonpolar FAME and polar FAME) in milk samples from ewes fed diets supplemented with $5.1 \%$ sunflower oil for $28 \mathrm{~d}$. IS = internal standard.

1 of the compounds of interest in the polar fraction, where $\mathrm{C} 21: 0$ was present as the internal standard. In other samples (chromatograms not shown), C24:0 or C20:5 eluting in total FAME at retention times close to those of polar peaks of interest were also separated in the nonpolar fraction. In all milk fats analyzed and as shown in this example, FAME found at 7.5 and $9.1 \mathrm{~min}$ (Figure 1) were entirely isolated in the polar fraction and no nonpolar compounds eluted at such retention times.

Figure 2 depicts a partial GC-MS chromatogram showing the oxygenated compounds that were identified in all polar fractions analyzed. Two chromatograms were overlapped, corresponding to group 4 (milk fat from ewes fed a diet supplemented with $2.5 \%$ sunflower oil plus $1.6 \%$ microalgae for $21 \mathrm{~d}$ ) and group 5 (milk fat from ewes fed a diet supplemented with $3 \%$ olive oil Ca soaps for $48 \mathrm{~d}$ ).

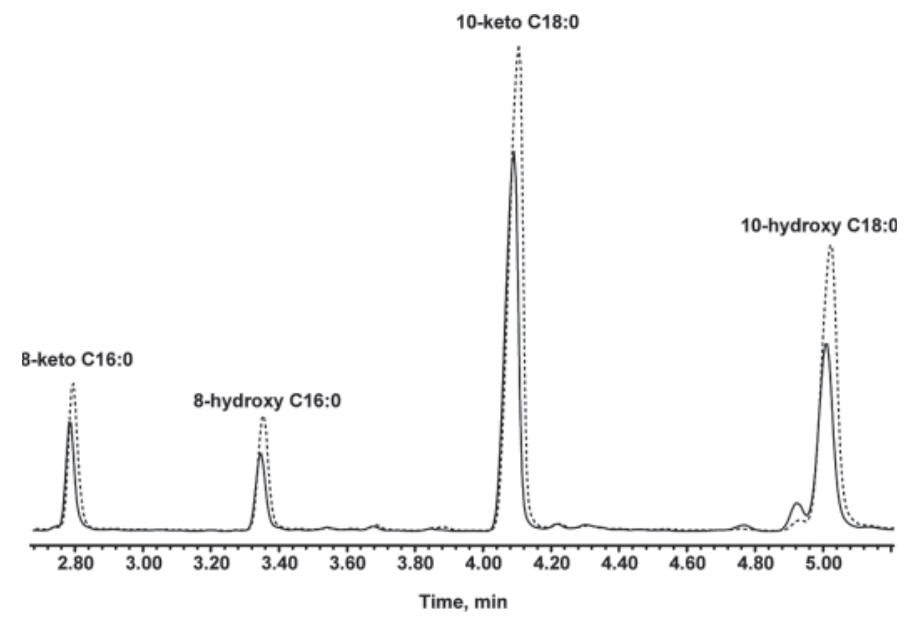

Figure 2. Gas chromatography-mass spectrometry chromatograms of polar fatty acid methyl ester fractions after isolation by solid-phase extraction in milk samples from ewes fed diets supplemented with $3 \%$ DM of olive oil Ca soaps for $48 \mathrm{~d}$ (dotted line) or with $2.5 \%$ sunflower oil plus $1.6 \%$ microalgae for $21 \mathrm{~d}$ (solid line).

The mass spectra of the 4 main peaks are shown in Figure 3. The structure of the first peak eluting on the chromatogram was assigned to 8-ketopalmitic acid methyl ester. The mass spectra of this compound are virtually identical to the spectrum of methyl 8-ketopalmitate in the spectral libraries of the mass spectrometer used. Furthermore, the most relevant ions of this spectrum were in concurrence with those reported by Weihrauch et al. (1974) for 8-ketopalmitic FA.

The second peak eluting in Figure 2 was assigned to 8-hydroxypalmitic acid methyl ester, a compound already described in the American Oil Chemists' Society (AOCS) Lipid Library (http://lipidlibrary.aocs.org). The key fragmentation ion is at mass-to-charge ratio $(m / z)=173$, originated by $\alpha$ cleavage between carbons 9 and 10 , whereas $m / z=141$ is formed from this latter by further fragmentation with the loss of methanol. In addition, the ion at $m / z=144$ is formed by a similar cleavage $\alpha$ to the carbon carrying the hydroxyl group, following protonation.

The mass spectrum of the biggest peak plotted in Figure 3 is characterized by a very weak molecular ion at $m / z 312$ and a fragment at $m / z 281$ corresponding to loss of a methoxy group from the ester moiety. Key ions are $\alpha$-cleavage fragments next to the mid-chain carbonyl group: $m / z 199$ and 141 . This mass spectrum is very similar to the spectrum of methyl 10-ketostearate showed in the AOCS Lipid Library (http://lipidlibrary. aocs.org) and largely consistent with the spectrum of 10-ketostearic acid found and published by Barakat et al. (1994) in lacustrine sediments.

The last peak eluting at the end of the chromatogram was identified as 10-hydroxystearic acid methyl 

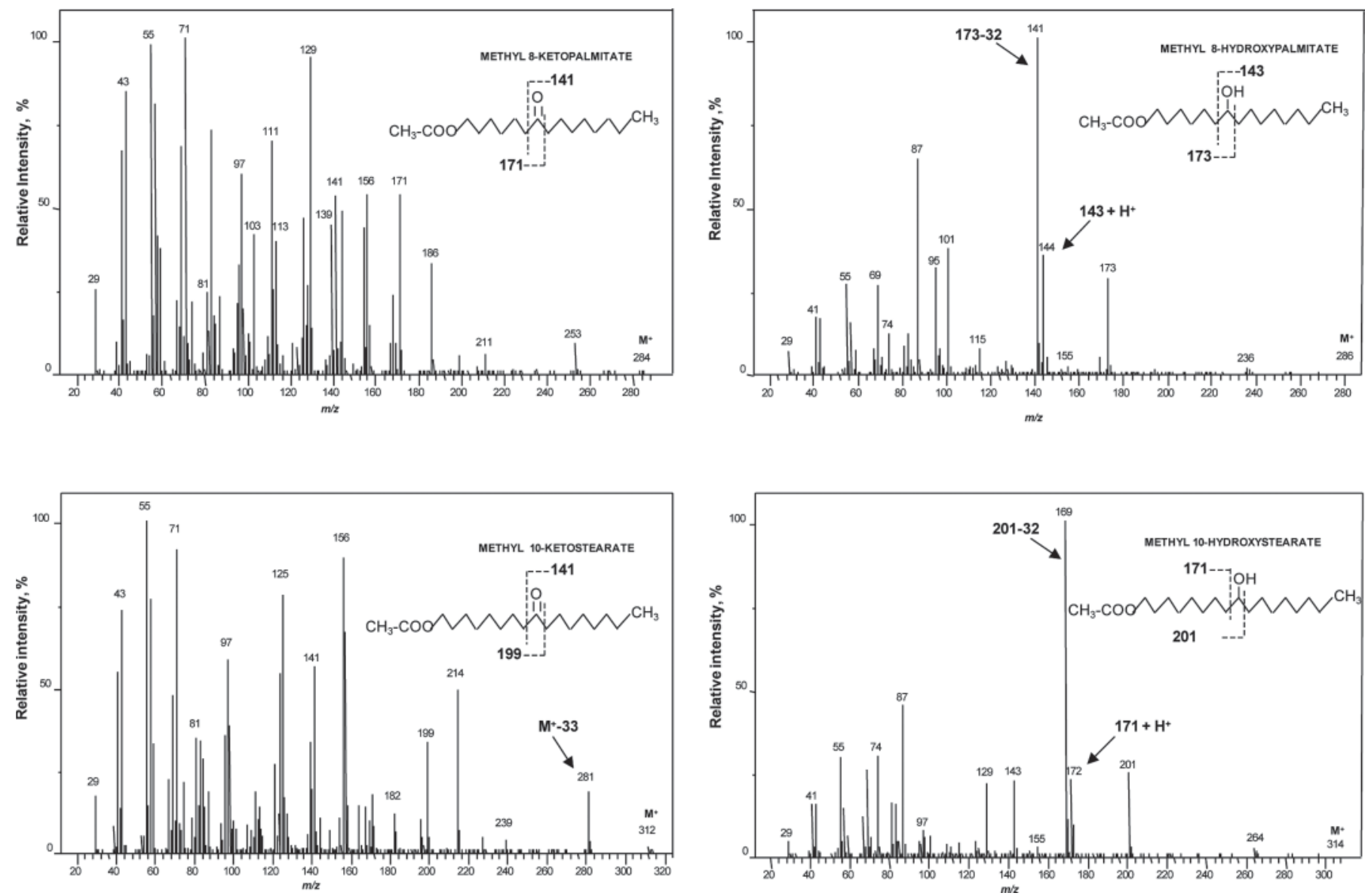

Figure 3. Electron impact ionization mass spectra of 8-ketopalmitic, 8-hydroxypalmitic, 10-ketostearic, and 10-hydroxystearic acid methyl esters in milk samples from ewes fed diets supplemented with $2.5 \%$ sunflower oil plus $1.6 \%$ microalgae for $21 \mathrm{~d}$. $\mathrm{m} / z=$ mass-to-charge ratio.

ester. To our knowledge, this is the first report showing the presence of this compound in milk fat. Significant peaks at $m / z$ values of 169,172 , and 201 would be indicative of the presence of a hydroxyl group at carbon 10. The spectrum found for this peak is in agreement with the data on the mass spectra of 10-hydroxystearic acid methyl ester published by Ryhage and Stenhagen (1960) and by Wallen et al. (1962). Occasionally, a small peak eluted just before the peak of 10-hydroxystearic acid methyl ester (Figure 2), but mass spectrum did not allow unequivocal identification.

\section{Variability of Oxygenated FAME in Milk Fats}

The oxygenated FA described above were detected in most of the milk fats analyzed. However their contents varied according to the type of samples. Table 2 shows the quantitative data obtained for milk fats from ewes fed diets supplemented with $3 \%$ olive, soybean, palm, and linseed oils. When FAME were analyzed directly by GC using a CP-Sil 88 column to determine milk fatty acid profile, 10-ketostearic acid eluted at $117 \mathrm{~min}$ but 10-hydroxysteraric acid could not be detected. However, SPE-GC using a DB-Wax column allowed determination of both 10-ketostearic acid and 10-hydroxysteraric acid as well as other minor oxygenated FA. 10-Ketostearic acid was the most abundant in all samples, followed by 10-hydroxystearic acid. The highest levels of both FA were obtained for diets enriched in olive oil (Table 2), whereas intermediate values were obtained for supplementation with soybean and linseed oils, and the lowest levels found for palm oil, a source of oil enriched in saturated FA. The inclusion in the goat diet of $4 \%$ high-oleic sunflower oil, of similar FA composition as olive oil, also led to increased levels of oleic acid along with 10-ketostearic acid and 10-hydroxystearic acid, these latter 2 showing as high as 10-fold-higher concentration in milk fat as compared with the control (nonsupplemented) diets (Table 3). Also, contents of 8-ketopalmitic acid and 8-hydroxypalmitic acid were markedly increased. In contrast, the addition of sunflower or linseed oils on diets did not practically enhance concentrations of oxygenated FA in milk. 
Table 2. Concentration of fatty acids ( $\mathrm{g} / 100 \mathrm{~g}$ of total fatty acid methyl esters) in milk from individual ewes fed diets supplemented with $4 \%$ olive, soybean, linseed, and palm oils (DM basis) ${ }^{1}$

\begin{tabular}{|c|c|c|c|c|}
\hline \multirow[b]{2}{*}{ Fatty acid } & \multicolumn{4}{|c|}{ Oil added to diet } \\
\hline & Olive & Soybean & Linseed & Palm \\
\hline \multicolumn{5}{|l|}{ GC } \\
\hline C16:0 & 22.48 & 22.41 & 20.74 & 32.54 \\
\hline cis-9 C16:1 & 0.99 & 0.84 & 0.72 & 1.58 \\
\hline trans-11 C18:1 & 2.38 & 8.55 & 6.90 & 0.90 \\
\hline trans-10 C18:1 & 0.90 & 0.94 & 0.48 & 0.43 \\
\hline cis-9 C18:1 & 24.98 & 15.62 & 15.70 & 15.37 \\
\hline 10-Keto C18:0 & 0.09 & 0.06 & 0.05 & 0.02 \\
\hline \multicolumn{5}{|l|}{$\mathrm{SPE}+\mathrm{GC}$} \\
\hline 8-Keto C16:0 & 0.04 & 0.03 & 0.04 & 0.02 \\
\hline 8-Hydroxy C16:0 & 0.02 & 0.02 & 0.03 & 0.02 \\
\hline 10-Keto C18:0 & 0.15 & 0.11 & 0.11 & 0.04 \\
\hline 10-Hydroxy C18:0 & 0.09 & 0.06 & 0.07 & 0.04 \\
\hline
\end{tabular}

${ }^{1}$ Determined by GC using a 100 CP-Sil 88 column (GC; Varian Inc., Middelburg, the Netherlands) and by GC using a 30-m DB-Wax column (J\&W Scientific Products GmbH, Köln, Germany) after isolation of the polar fraction by solid-phase extraction (SPE + GC).

The dietary incorporation of higher doses $(5.1 \%)$ of a source of linoleic acid (sunflower oil), also moderately increased the levels of 10-ketostearic and 10-hydroxystearic acids (up to 0.18 and $0.12 \%$ respectively) in milk after $28 \mathrm{~d}$ (Table 4). In these samples, a sharp increase (12-fold) of the trans-10 C18:1 contents as well as a decrease in trans-11 C18:1 was found at the end of the supplementation period, an evidence of a shift in the biohydrogenation pathways.

The highest levels of oxygenated compounds were found in milk coming from animals fed diets supplemented with sunflower oil plus microalgae (Table 5) and, mainly, from some individual ewe milk samples from animals fed Ca soap olive oil-supplemented diets (Table 6). In both experiments, the milk samples richest in trans-10 C18:1 and poorest in oleic acid contained the highest concentrations of 10-ketostearic and 10-hydroxystearic acids. Levels of keto FA of a magnitude about $1 \%$ or higher have not been documented previously in dairy products. Brechany and Christie (1992) detected trace amounts of a great number of keto FA in Cheddar cheese (16 and $66 \mathrm{mg} / \mathrm{kg}$ for 8-ketopalmitic and 10-ketostearic acids, respectively). However, evidence of occurrence of hydroxy FA was not provided.

\section{Origin of Keto and Hydroxy FA}

Correlation coefficients between oxygenated and non-oxygenated FA for all FA reported in Tables 2 to 6 scarcely showed strong relationships. Very high correlation coefficients were, however, obtained between 10-ketostearic and 8-ketopalmitic acids $\left(\mathrm{R}^{2}=0.93 ; P<\right.$

Table 3. Concentration of fatty acids (g/100 g of total fatty acid methyl esters) in milk from individual goats fed an unsupplemented diet (control) and diets supplemented with $4 \%$ high-oleic sunflower (HOS), sunflower, and linseed oils (DM basis $)^{1}$

\begin{tabular}{|c|c|c|c|c|}
\hline \multirow[b]{2}{*}{ Fatty acid } & \multicolumn{4}{|c|}{ Oil added to diet } \\
\hline & Control & HOS & Sunflower & Linseed \\
\hline \multicolumn{5}{|l|}{$\mathrm{GC}$} \\
\hline C16:0 & 32.72 & 20.06 & 26.22 & 26.23 \\
\hline cis-9 C16:1 & 1.18 & 0.95 & 0.83 & 0.67 \\
\hline trans-11 C18:1 & 1.80 & 1.35 & 4.74 & 5.45 \\
\hline trans-10 C18:1 & 0.41 & 0.60 & 0.54 & 0.37 \\
\hline cis-9 C18:1 & 12.82 & 24.47 & 14.83 & 14.54 \\
\hline 10-Keto C18:0 & 0.05 & 0.56 & 0.10 & 0.10 \\
\hline \multicolumn{5}{|l|}{$\mathrm{SPE}+\mathrm{GC}$} \\
\hline 8-Keto C16:0 & 0.04 & 0.18 & 0.06 & 0.06 \\
\hline 8-Hydroxy C16:0 & 0.00 & 0.11 & 0.03 & 0.02 \\
\hline 10-Keto C18:0 & 0.07 & 0.81 & 0.15 & 0.13 \\
\hline 10-Hydroxy C18:0 & 0.03 & 0.34 & 0.08 & 0.06 \\
\hline
\end{tabular}

${ }^{1}$ Determined by GC using a 100 CP-Sil 88 column (GC; Varian Inc., Middelburg, the Netherlands) and by GC using a 30-m DB-Wax column (J\&W Scientific Products GmbH, Köln, Germany) after isolation of the polar fraction by solid-phase extraction (SPE + GC). 
Table 4. Concentration of fatty acids ( $\mathrm{g} / 100 \mathrm{~g}$ of total fatty acid methyl esters) in bulk milk from ewes fed an unsupplemented diet (control) and diets supplemented with $5.1 \%$ sunflower oil (DM basis) for 7, 14, and $28 \mathrm{~d}^{1}$

\begin{tabular}{|c|c|c|c|c|}
\hline \multirow[b]{2}{*}{ Fatty acid } & \multirow[b]{2}{*}{ Control } & \multicolumn{3}{|c|}{ Duration of supplementation } \\
\hline & & $7 \mathrm{~d}$ & $14 \mathrm{~d}$ & $28 \mathrm{~d}$ \\
\hline \multicolumn{5}{|l|}{ GC } \\
\hline C16:0 & 27.79 & 19.40 & 19.75 & 20.37 \\
\hline cis-9 C16:1 & 1.19 & 0.83 & 0.82 & 0.90 \\
\hline trans-11 C18:1 & 1.52 & 12.24 & 10.35 & 8.88 \\
\hline trans-10 C18:1 & 0.63 & 1.81 & 4.89 & 8.43 \\
\hline cis-9 C18:1 & 11.74 & 13.27 & 14.01 & 14.19 \\
\hline 10-Keto C18:0 & 0.00 & 0.08 & 0.09 & 0.11 \\
\hline \multicolumn{5}{|l|}{$\mathrm{SPE}+\mathrm{GC}$} \\
\hline 8-Keto C16:0 & 0.00 & 0.03 & 0.03 & 0.04 \\
\hline 8-Hydroxy C16:0 & 0.00 & 0.03 & 0.02 & 0.04 \\
\hline 10-Keto C18:0 & 0.00 & 0.10 & 0.13 & 0.18 \\
\hline 10-Hydroxy C18:0 & 0.00 & 0.09 & 0.10 & 0.12 \\
\hline
\end{tabular}

${ }^{1}$ Determined by GC using a 100 CP-Sil 88 column (GC; Varian Inc., Middelburg, the Netherlands) and by GC using a 30-m DB-Wax column (J\&W Scientific Products GmbH, Köln, Germany) after fractionation by solidphase extraction $(\mathrm{SPE}+\mathrm{GC})$.

0.001), 10-hydroxystearic and 8-ketopalmitic acids $\left(\mathrm{R}^{2}\right.$ $=0.93 ; P<0.001)$, and 10-ketostearic and 10-hydroxystearic acids $\left(\mathrm{R}^{2}=0.95 ; P<0.001\right)$. Strong relationships were also found for 8-hydroxypalmitic and 8-ketopalmitic $\left(\mathrm{R}^{2}=0.85 ; P<0.001\right)$, 8-hydroxypalmitic and 10-hydroxystearic acids $\left(\mathrm{R}^{2}=0.84 ; P<0.001\right)$; and 8-hydroxypalmitic and 10-ketostearic acids $\left(\mathrm{R}^{2}=\right.$ 0.77; $P<0.001)$.

The conversion of 10-hydroxystearic to 10-ketostearic FA is a well known route that occur in the ruminant digestive tract by some ruminal bacteria as part of their detoxification mechanisms (Jenkins et al., 2006; McKain et al., 2010). The origin of 8-ketopalmitic acid is, however, uncertain. Potentially, it might derive from cis-9 C16:1 by hydration of the double bond. However the lack of correlation between 8-ketopalmitic and cis-9
C16:1 $\left(\mathrm{R}^{2}=0.17 ; P=0.44\right)$ would not support the existence of this pathway. As enzyme systems would be expected to be too specific in their properties to be able to insert keto groups in a wide range of positions in an aliphatic chain, it may be possible that the less abundant 8-ketopalmitic acid could derive from the 10-ketostearic (Figure 4) by partial $\beta$-oxidation (Brechany and Christie, 1992). Following with this reasoning we could also argue that 8-hydroxypalmitic would be originated in the tissues by $\beta$-oxidation from the 10 -hydroxystearic FA generated in the rumen (Figure 4).

Results of 10-ketostearic acid reported in Tables 2 and 3 could be mostly attributed to the presence of oleic acid in the rations. Oleic acid would be converted to 10-ketostearic in the rumen via 10-hydroxystearic and, then, both oxygenated FA would be transferred

Table 5. Concentration of fatty acids ( $\mathrm{g} / 100 \mathrm{~g}$ of total fatty acid methyl esters) in bulk milk from ewes fed an unsupplemented diet (control) and diets supplemented with $2.5 \%$ sunflower oil plus $0.8 \%$ or $1.6 \%$ microalgae (DM basis) for 7 or $21 \mathrm{~d}^{1}$

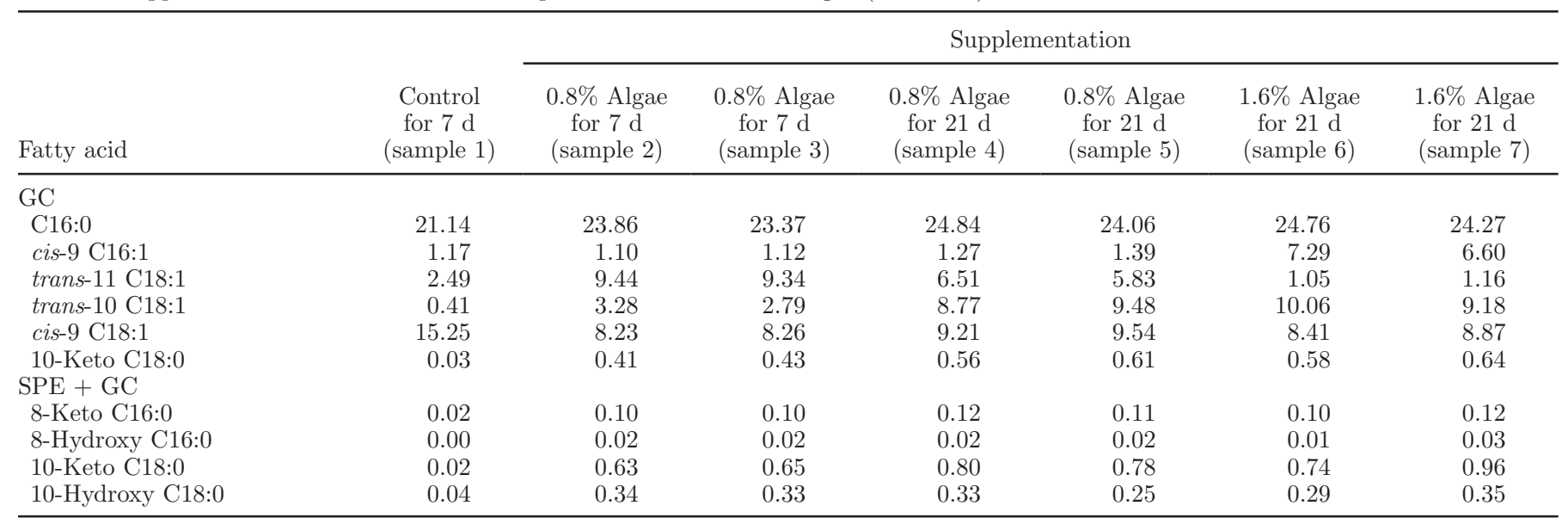

${ }^{1}$ Determined by GC using a 100 CP-Sil 88 column (GC; Varian Inc., Middelburg, the Netherlands) and by GC using a 30-m DB-Wax column (J\&W Scientific Products GmbH, Köln, Germany) after isolation of the polar fraction by solid-phase extraction (SPE + GC). 


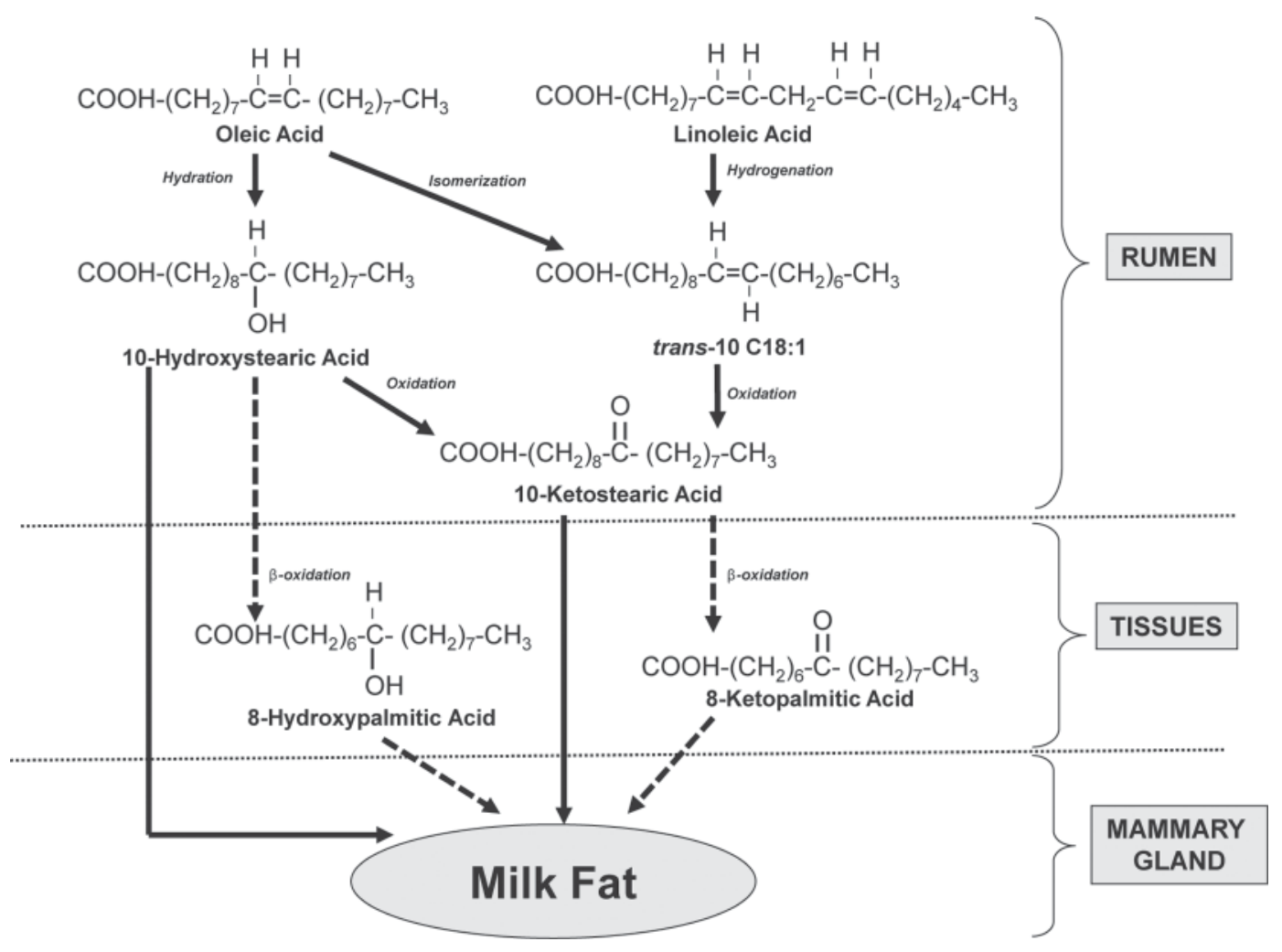

Figure 4. Pathways of formation of oxygenated fatty acids in ruminants. Solid arrows represent the main metabolic route, whereas the dashed arrows represent a putative route including all of the oxygenated compounds detected in the present study.

to the mammary gland (Figure 4). Although different experiments have indicated that oleic acid undergoes an extensive isomerization by rumen microorganisms yielding preferably several trans C18:1 isomers (Mosley et al., 2002; Gómez-Cortés et al., 2008), mainly trans-10 C18:1 (Figure 4), other researchers have also documented the ability of different species of ruminal bacteria to hydrate oleic acid and generate 10-keto- stearate as a major end product (Hudson et al., 1995, 2000; McKain et al., 2010). Furthermore, Jenkins et al. (2006) reported the formation of 10-hydroxystearic and 10-ketostearic acids from oleic acid transformation by ruminal microorganisms, and showed that their accumulation in ruminal contents is directly related to the extent of oleic acid input and transformation in the rumen.

Table 6. Concentration of fatty acids ( $\mathrm{g} / 100 \mathrm{~g}$ of total fatty acid methyl esters) in milk from 4 individual ewes fed a diet supplemented with $3 \%$ olive oil Ca soaps (DM basis) for $48 \mathrm{~d}^{1}$

\begin{tabular}{|c|c|c|c|c|}
\hline Fatty acid & Ewe 1 & Ewe 2 & Ewe 3 & Ewe 4 \\
\hline \multicolumn{5}{|l|}{ GC } \\
\hline $\mathrm{C} 16: 0$ & 17.98 & 20.39 & 23.67 & 26.25 \\
\hline cis-9 C16:1 & 0.79 & 0.86 & 1.11 & 1.09 \\
\hline trans-11 C18:1 & 1.69 & 2.64 & 5.54 & 1.83 \\
\hline trans-10 C18:1 & 0.92 & 0.80 & 3.28 & 5.99 \\
\hline cis-9 C18:1 & 22.32 & 24.36 & 10.05 & 13.79 \\
\hline 10-Keto C18:0 & 0.12 & 0.11 & 0.98 & 1.12 \\
\hline \multicolumn{5}{|l|}{$\mathrm{SPE}+\mathrm{GC}$} \\
\hline 8-Keto C16:0 & 0.04 & 0.04 & 0.26 & 0.24 \\
\hline 8-Hydroxy C16:0 & 0.04 & 0.03 & 0.19 & 0.19 \\
\hline 10-Keto C18:0 & 0.19 & 0.18 & 1.52 & 1.56 \\
\hline 10-Hydroxy C18:0 & 0.13 & 0.11 & 0.80 & 0.73 \\
\hline
\end{tabular}

${ }^{1}$ Determined by GC using a 100 CP-Sil 88 column (GC; Varian Inc., Middelburg, the Netherlands) and by GC using a 30-m DB-Wax column (J\&W Scientific Products GmbH, Köln, Germany) after isolation of the polar fraction by solid-phase extraction (SPE + GC). 
The high level of oxygenated FA in samples 3 and 4 (Table 6) could be only partially attributed to the presence of oleic acid in the rations, known the limited protection what $\mathrm{Ca}$ salts supply in the rumen to the dietary lipids. In comparison, the extremely low percentage of oxygenated FA obtained in samples 1 and 2 (Table 6) would denote the prominent role played by the microbial flora present in the rumen. Thus, as results correspond to milk samples from individual ewes, differences among animals in the microorganisms present in the digestive tract (Hudson et al., 2000) and, particularly, in bacteria able to convert oleic acid to 10-hydroxystearic acid, would account for substantial differences in contents of oxygenated products in milk.

Due to the very low contents of oleic acid, other mechanisms had to be involved in the high percentages of oxygenated compounds found in the milk fat samples reported in Table 5. These results are consistent with a previous study where the supplementation with marine oils enriched in long-chain n-3 FA was associated with a time-dependent increase of 10-ketostearic acid in ewe ruminal digesta (Toral et al., 2010). Early research (Kitessa et al., 2001) reported that tuna oil promoted the formation of 10-hydroxystearic acid in the rumen of sheep, too.

The key to understanding the data in Table 5 and those in Table 4 would lie in the availability of trans-10 C18:1. This trans monounsaturated FA, commonly generated in the rumen by a shift in the biohydrogenation pathways of linoleic acid, could be a precursor of some oxygenated FA by alternative metabolic routes (Figure 4). In fact, McKain et al., (2010) revealed that Propionibacterium acnes would be, at least, one bacterium in the rumen responsible for the hydration of trans-10 C18:1 to form 10-hydroxystearic acid, and after be metabolized to 10-ketostearic acid. A previous study (Mortimer and Niehaus, 1972) also reported the conversion of trans-10 C18:1 to 10-hydroxystearic acid by a soluble enzyme preparation from a pseudomonad. The most moderate increases in oxygenated FA observed after $28 \mathrm{~d}$ in ewe milk from animals fed a highly sunflower oil-supplemented diet (Table 4), despite the high levels of trans-10 C18:1, lead again to speculation that key species to convert trans-10 C18:1 to 10-hydroxystearic acid were absent in the digestive tract. Propionibacterium acnes is one of the less numerous ruminal species (McKain et al., 2010), and it is questionable whether alterations in the growth of this species alone can account for the changes in ruminal FA outflow known to occur in ruminants fed diets containing a high proportion of concentrates or oil supplements rich in unsaturated FA.

\section{CONCLUSIONS}

The method proposed enabled quantitative determination of minor oxygenated FA esterified in milk fat triacylglycerols that result from ruminant lipid metabolism. Overall, data obtained in this study illustrated that 10-ketostearic acid is regularly present in milk coming from animals fed different sources of oilsupplemented diets and its presence is closely linked to the occurrence of 10-hydroxystearic acid, first reported in milk fat in this study. Both FA could be products of alternative pathways of transformation of oleic acid and trans-10 C18:1 in the rumen. The detection in milk fat of remarkable amounts of 8-ketopalmitic and 8-hydroxypalmitic supports the existence of a route of conversion, via partial $\beta$-oxidation, from 10-ketostearic and 10-hydroxystearic respectively.

\section{ACKNOWLEDGMENTS}

The authors thank the Ministerio de Ciencia e Innovación (Madrid, Spain; Projects Ref. AGL2008-04805, AGL2010-18307 and Consolider Ingenio 2010 Ref. CSD/2007/00063 FUN-C-FOOD), and the Comunidad Autónoma de Madrid (Project Ref. S2009-AGR-1469 and S2009-AGR-1464) for their financial support.

\section{REFERENCES}

Abe, A., and K. Sugiyama. 2005. Growth inhibition and apoptosis induction of human melanoma cells by omega-hydroxy fatty acids. Anticancer Drugs 16:543-549.

Barakat, A. O., T. M. Peakman, and J. Rullkötter. 1994. Isolation and structural characterization of 10-oxo-octadecanoic acid in some lacustrine sediments from the Nördlinger Ries (southern Germany). Org. Geochem. 21:841-847.

Berdeaux, O., G. Márquez-Ruiz, and C. Dobarganes. 1999. Selection of methylation procedures for quantitation of short-chain glycerolbound compounds formed during thermoxidation. J. Chromatogr. A $863: 171-181$.

Brechany, E. Y., and W. W. Christie. 1992. Identification of the saturated oxo fatty acids in cheese. J. Dairy Res. 59:57-64.

Casali, E., N. Gesmundo, G. Farruggia, A. Spisni, and L. Masotti. 1994. Hydroxystearic acid effects on CDC2/histone H1 kinase activity in C108 carcinoma cells. Biochem. Biophys. Res. Commun. 203:1385-1391.

Gesmundo, N., E. Casali, G. Farruggia, A. Spisni, and L. Masotti. 1994. In vitro effects of hydroxystearic acid on the proliferation of HT29 and I407 cells. Biochem. Mol. Biol. Int. 33:705-712.

Gómez-Cortés, P., P. Frutos, A. R. Mantecón, M. Juárez, M. A. de la Fuente, and G. Hervás. 2008. Addition of olive oil to dairy ewe diets: Effect on milk fatty acid profile and animal performance. J. Dairy Sci. 91:3119-3127.

Hudson, J. A., Y. Cai, R. J. Corner, B. Morvan, and K. N. Joblin. 2000. Identification and enumeration of oleic and linoleic acid hydrating bacteria in the rumen of sheep and cows. J. Appl. Bacteriol. 88:286-292.

Hudson, J. A., C. A. M. MacKenzie, and K. N. Joblin. 1995. Conversion of oleic acid to 10-hydroxystearic acid by two species of ruminal bacteria. Appl. Microbiol. Biotechnol. 44:1-6. 
ISO-IDF. 2002a. Milk fat-Preparation of fatty acid methyl esters. International Organization for Standardization (ISO) standard 15884-IDF 182: 2002. International Dairy Federation, Brussels, Belgium.

ISO-IDF. 2002b. Milk fat-Determination of the fatty acid composition by gas-liquid chromatography. International Organization for Standardization (ISO) standard 15885-IDF 184: 2002. International Dairy Federation, Brussels, Belgium.

Jenkins, T. C., A. A. AbuGhazaleh, S. Freeman, and E. J. Thies. 2006. The production of 10-hydroxystearic and 10-ketostearic acids is an alternative route of oleic acid transformation by the ruminal microbiota in cattle. J. Nutr. 136:926-931.

Jensen, R. G. 2002. The composition of bovine milk lipids: January 1995 to December 2000. J. Dairy Sci. 85:295-350.

Jenske, R., and W. Vetter. 2008. Gas chromatography/electron-capture negative ion mass spectrometry for the quantitative determination of 2- and 3-hydroxy fatty acids in bovine milk fat. J. Agric. Food Chem. 56:5500-5505.

Kitessa, S. M., S. K. Gulati, J. R. Ashes, E. Fleck, T. W. Scott, and P. D. Nichols. 2001. Utilisation of fish oil in ruminants I. Fish oil metabolism in sheep. Anim. Feed Sci. Technol. 89:189-199.

Luna, P., M. Juárez, and M. A. de la Fuente. 2005. Validation of a rapid milk fat separation method to determine the fatty acid profile by gas chromatography. J. Dairy Sci. 88:3377-3381.

Marmesat, S., J. Velasco, and M. C. Dobarganes. 2008. Quantitative determination of epoxy acids, keto acids and hydroxy acids formed in fats and oils at frying temperatures. J. Chromatogr. A 1211:129-134.
McKain, N., K. J. Shingfield, and R. J. Wallace. 2010. Metabolism of conjugated linoleic acids and 18:1 fatty acids by ruminal bacteria: Products and mechanisms. Microbiology 156:579-588.

Mortimer, C. E., and W. G. Niehaus Jr. 1972. Enzymatic isomerization of oleic acid to trans- $\Delta^{10}$-octadecenoic acid. Biochem. Biophys. Res. Commun. 49:1650-1656.

Mosley, E. E., G. L. Powell, M. B. Riley, and T. C. Jenkins. 2002. Microbial biohydrogenation of oleic acid to trans isomers in vitro. J. Lipid Res. 43:290-296.

Parks, O. W. 1977. Isolation and characterization of nonesterified 3-hydroxy fatty acid composition in milk. J. Dairy Sci. 60:718-720.

Ryhage, R., and E. Stenhagen. 1960. Mass spectrometric studies. VI. Methyl esters of normal chain oxo-, hydroxy-, methoxy- and epoxy-acids. Ark. Kemi 15:545-574.

SAS Institute. 2004. SAS User's Guide: Statistics. SAS Inst. Inc., Cary, NC.

Toral, P. G., K. J. Shingfield, G. Hervás, V. Toivonen, and P. Frutos. 2010. Effect of fish oil and sunflower oil on rumen fermentation characteristics and fatty acid composition of digesta in ewes fed a high concentrate diet. J. Dairy Sci. 93:4804-4817.

Wallen, L. L., R. G. Benedict, and R. W. Jackson. 1962. The microbiological production of 10-hydroxystearic acid from oleic acid. Arch. Biochem. Biophys. 99:249-253.

Weihrauch, J. L., C. R. Brewington, and D. P. Schwartz. 1974. Trace constituents in milk fat: Isolation and identification of oxofatty acids. Lipids 9:883-890. 